\title{
A Multi-Channel System ArChitecture For BANKING
}

\author{
Chris Pavlovski
}

IBM, Sydney, NSW, Australia

\begin{abstract}
Financial institutions have increased dependence upon the technology solutions that enable their financial products and services. The proliferation of Internet technologies, mobile devices, and competition from international commerce have placed increased pressure up banking and financial institutions to ensure that competitive leadership is maintained. A key challenge facing banking and finance is how to adopt the new Information and Communications Technologies (ICT) within the organization in a timely manner whilst not disrupting the embedded solutions that provide core banking capabilities to operate the business. In this paper we propose a multi-channel architecture for financial institutions such as banking. The architecture is based upon our industry experience in developing multi-channel solutions in similar industries and is refined further here based upon our experiences in banking. The proposed architecture may be used to facilitate decisions on how best to deploy new and emerging multi-channel technologies within the banking environment, providing a means for assessing how to ensure effective use of existing investments in systems and technologies. The solution may be used as a blueprint for banking institutions in developing their multi-channel strategies; addressing the incumbent, emerging, and future channels of banking distribution.
\end{abstract}

\section{KEYWORDS}

Banking, Multi-channel Architecture, Pervasive Computing, Emerging Technologies

\section{INTRODUCTION}

Banking and financial institutions have undergone significant change to accommodate the diverse nature in which distribution channels have been used to engage their customers. As new technologies emerge in the market, consumers are adopting these innovations to conduct their personal and business activities. Interacting with banking systems either directly or indirectly, such as point of sale, has placed increased pressure upon the banking solutions that service these transactions. Consumers are more aware and ready to take up newer technologies and hence financial institutions that are able to accommodate their consumers are positioned better to cater to the demands of the customer base, helping to mitigate erosion by competing entities. The ability of financial institutions to adopt new banking channels is often constrained by the systems and architectures in place of incumbent technologies. Such constraints may be considered generally as a cross-industry challenge. Hence, adopting strategies that foster deployment of new technologies that integrate with core banking systems and still be flexible to cater to a rapidly changing mobile device market will help to ensure that competitive reach to the consumer is maintained.

The traditional banking channels such as branch, Automatic Teller Machines (ATM), and call centres have undergone significant change in the types of technologies used to support these domains. More recent channels such as the Internet, provide consumers with the ability to DOI : $10.5121 /$ ijcsea.2013.3501 
conduct a range of banking functions remotely. As technologies improved, these systems were supported with on-line chat and full banking services such as bill payment, interbank transfers and payment card support. The emergence of mobile devices as a core platform for accessing accounts has brought a new set of demands upon banking services. The extension of mobility and alternative form factors requires an additional set of infrastructure to support and cater to the demands of these solutions. Additionally, it is likely that as newer forms of banking channels emerge a combination of the exiting and newer technologies shall require consideration in the overall technology architecture adopted by financial institutions. Hence, we suggest that the information and communications technologies necessary to support the multiple distribution channels requires further consideration in order to effectively enable a bank to support an agile channel presence with the customer whilst providing a stable core banking platform and environment. Moreover, we wish to preserve application stability in the presence of a highly dynamic and changing device market.

We outline in this paper a multi-channel architecture for banking that is designed to accommodate a flexible and dynamic device market, whilst supporting a stable set of core banking platforms. We draw upon work done on multi-channel delivery systems from several industries that have had a need to support distribution of content to multiple devices and channels. We model the banking transactions to develop an architecture and framework that may be used by both banking and other financial institutions. It is hoped that the proposed architecture may serve as a blueprint to other financial groups intending to refine their multi-channel approach. Hence we view the main contributions of this paper as:

1. Identify and classify the traditional and emerging distribution channels applied in banking and finance.

2. Review and assess the technologies and frameworks that are presently available to support a multi-channel distribution system.

3. Present an architectural view and model, as a blueprint, for developing a multi-channel solution in financial services.

In the next section we review the literature related to multi-channel delivery and banking architectures in general. This is then followed in section 3 by a discussion of the traditional and emerging distribution channels that define the scenarios that the system is intended to support. The technologies and framework available to support deployment of multi-channel solutions are then discussed in section 4 . We then outline in section 5 our proposed multi-channel architecture for banking, by applying the related standards together with our experiences in deploying industry wide enterprise architectures and multi-channel solutions. In section 6 we analyze the blueprint against several use case scenarios, describing how the system behaves through a set of system interaction diagrams. Finally, in section 7 we summarize some of the key points regarding the development of multi-channel architectures and discuss areas of further work.

\section{RELATED WORK}

The literature relating to multi-channel architectures for banking is limited; however the notion of service delivery over a range of distribution channels has been treated by the telecommunications industry previously with the technology and systems associated with these solutions referred to as service delivery platforms [1]. While there is extensive work for banking on enterprise architectures [2, 3, 4], which focus on broader topics in business, process and technology for banking, the published works do not fully address the architectures associated with multi-channel delivery. Hence, we wish to address this area in more detail by proposing and analyzing a multichannel system architecture for banking. 
Although there is less work directly addressing multi-channel architecture in banking, there are several related works that address similar domains either for banking or related industries, these areas include the banking channels for Internet, mobile devices, and other emerging technologies; we now briefly discuss these. In [5] the channel domain of mobile banking is assessed, where the authors characterize the customer requirements for mobile use. The authors also remark that during the emerging years of mobile banking it was the most important distribution and communications channel for retail banking. Further analysis on the impact of mobile banking also supports the projected growth in service take-up as the channel matures [6]. The authors also remark on the importance of using the mobile channel for marketing and customer retention. Design approaches for mobile device payments are disclosed in [7]. Two design alternatives are evaluated with consideration given to features such as cost, performance, and usability.

Other work that deals with security for banking channels, such as the Internet, describe an architecture for traditional security capabilities such as single sign on [8]. Some additional work on an end-to-end Public Key Infrastructure (PKI) for mobile banking is also proposed [9]. The paper outlines a framework to support several mobile data channels, analyzing the performance of a test implementation using several cryptographic algorithms. A software architecture is proposed for mobile computing in [10] with the protocols and frameworks defined at the user device, while usability and security is also highlighted as a key area of research for e-banking in [11]. Together these areas in security for banking will become increasingly more important as the number of channels increase revealing new threats.

Finally, there is a contribution exploring the application of UML to support a multi-channel architecture design [12]. The notion of a virtual bank is explored and the use of design tools such as UML based Use Cases are assessed to determine effectiveness for aiding design for multichannel systems. Although the focus of previous work is on specific channels such as mobile and Internet with infrastructure capabilities such as security services, there does not appear to be detailed work on providing a comprehensive system architecture for multi-channel delivery. We seek to extend the previous work to address that gap and propose a reference architecture and blueprint that may be useful for building multi-channels systems that may also be extended in an easy way to cater to future distribution channels that emerge for banking.

\section{Traditional AND EMERging Distribution ChanNElS}

In this section we describe both the traditional and emerging banking channels, investigating the business driver and user scenarios of interaction as a basis for requirements.

\subsection{Traditional Channels}

Branch. The bank branch is the foundation distribution channel for banking, being transformed numerous times with each technology revolution. Today, many branches furnish a more open plan style of that is similar to the modern day shopping experience for customers.

Representative. Sales representatives both mobile and at bank branches will continue to form part of the personal experience that customers may access. In many ways these channels represents a mobile bank branch with access to many of the tools and systems for processing customer forms and requests.

IVR. Interactive Voice Response Systems server two key purposes, i) they act as a traffic filter for directing customer phone calls to the appropriate call center representative, and ii) they provide an automated voice banking system for conducting several financial transactions. 
Mail. Use of mail is still a vital part of the marketing channel for banking and is also used for distribution of customer related identifiers and cards. Customers may use mail for returning information, but often this is conducted in person at the branch or with more modern channels such as on-line banking.

Call Center. Servicing all forms of requests from customers, the modern day call center has representatives equipped with access to both on-line and core banking systems to perform all necessary functions in processing customer requirements.

ATM. Automatic Teller Machines are perhaps the first distribution channel that provided customers with an automated technology system for interacting with the bank for cash withdrawals. These systems still form a foundation for customer banking and are now complimented with several newer on-line systems.

\subsection{Emergent Channels}

Point of Sale (POS). Point of sale systems such as electronic funds transfer have been a mainstream channel for some time, however these have recently undergone change allowing customers to use point of sale as a means for cash withdrawal. Hence this is noted here as a more recent channel for banking.

Email. Electronic mail was initially used as a new channel for distribution, however given the significance of spam and malicious attack to obtain customer credentials this form of communication is largely being deprecated from major use. In most cases banks provide their own form of messaging, in lieu of email, that is accessible to customers using online accounts.

Internet. The advent of the Internet has and continues to transform they way all business is conducted. The Internet banking channel is increasingly becoming the core banking channel for conducting all forms of financial transactions, with many of the functions available in several form factors to cater for personal computers, mobile devices, and other emerging technologies.

On-line Chat. On line chat is often considered an extension of the Internet Channel however this differs sufficiently to warrant individual consideration. A text based message chat session allows customers and bank staff to interact in real-time to address immediate questions without the need to place a voice call to the call center. This provides context-aware customer support for on-line banking activities.

Mobile Device. This channel encompasses interactions via the mobile device including internet, SMS, and voice calls. The significant advances in mobile technology will enable rich user scenarios that encompass multi-modes of interaction (i.e. voice and data simultaneously), and also support for tablet based computing devices as these become more widely adopted as an accessory for most customers.

\section{TEChNOlogies AND Standards FOR MUlti-ChanNel BANKING}

With the growing dependence upon the device trends adopted by consumer a range of information and communication technologies, as well as associated standards, have become central components to banking and more importantly multi-channel distribution. The most recent technologies pertain to web enablement, however the emergence and rapid adoption of mobile devices and networks is changing the technical environment for many financial institutions. The following table (Table 1) briefly summarizes some of the more prominent technologies and standards in use. 
Table 1. Technologies and Standards for Multi-Channel Banking

\begin{tabular}{ll}
\hline \hline ICT & Description \\
\hline Internet & $\begin{array}{l}\text { Internet technologies such as web servers, on-line chat, authentication } \\
\text { servers, messaging gateways and proxies, enable on-line banking access to } \\
\text { customers over the Internet. }\end{array}$ \\
\hline Mobile & $\begin{array}{l}\text { Traditional cellular 3G and 4G mobile networks and wireless technologies to } \\
\text { support mobility. These systems are largely used to extend Internet } \\
\text { accessibility. }\end{array}$ \\
\hline RFID and NFC & $\begin{array}{l}\text { Near Field Computing (NFC) wireless communication based on Radio } \\
\text { Frequency Identification (RFID), used for contactless payment by major } \\
\text { credit card institutions. }\end{array}$ \\
\hline SOA & $\begin{array}{l}\text { Service Oriented Architecture is an approach for defining services consumed } \\
\text { by IT applications; which can be internally shared or externally accessed } \\
\text { over the Internet. }\end{array}$ \\
\hline TOGAF & $\begin{array}{l}\text { The Open Group Architecture Framework specifies both a process and } \\
\text { framework for defining enterprise and system architectures. }\end{array}$ \\
\hline BIAN & $\begin{array}{l}\text { Banking Industry Architecture Network defines a set of IT services based } \\
\text { upon a Service Oriented Architecture. }\end{array}$ \\
\hline NLU / NLP & $\begin{array}{l}\text { Natural Language Understanding \& Processing technologies extend } \\
\text { conventional voice recognition with natural speech. Traditional IVR is } \\
\text { directed speech and restrictive, whilst NLU technology supports unrestricted } \\
\text { (human-like) conversational interaction. }\end{array}$ \\
\hline EWallet & $\begin{array}{l}\text { Emerging use of mobile phones as a payment device, leveraging the } \\
\text { embedded SIM (subscriber identity module) smart card chip, where the } \\
\text { eWallet application is deployed. }\end{array}$ \\
\hline
\end{tabular}

We now discuss some of the emerging state of the art devices and technologies which may require consideration strategically. Some of these innovations, may not necessarily become an adopted approach, but gives a perspective on the potential for advances in technology that may require some support.

Mobile Applications. As mobile device technology has diversified the need has arisen to develop specific mobile applications for the various operating systems and devices on the market. As such the complexity associated with developing and deploying multiple applications, (i.e. Flash, Java, etc) has become an increasing challenge for banking technologists.

Television enabled Internet. Ability to accommodate much larger form factor as users will be equipped in the future with device capability to initially access a website on the mobile unit and when at home may transfer this to the television set, using hand gestures to transfer control to another device. A capability to transfer between devices will also require additional security measures to prevent malicious exploits.

Embedded Vehicle Devices. Embedded vehicle communication devices may be perhaps considered a further extension to mobile devices with several key differences. There is an increased dependence upon voice operated user interfaces, facilitated with natural language speech technologies, which provide a superior voice experience over traditional IVR or voice recognitions systems [13]. This is a firm requirement, given the restrictions on using devices to prevent distractions from operating the vehicle in transit. The form factor is likely to be similar to that of a Tablet, but may be also imbued upon Head up Displays (HUD). 
Electronic Wallets. Devices such as mobile phones are being positioned as an alternative to credit cards with more $3^{\text {rd }}$ party entrants into the financial transaction market. These are likely to be a nearer term device that requires support by the banking industry. Although some capabilities are an extension of existing mobile device, there are additional interactions with $3^{\text {rd }}$ parties who may be the account holder on behalf of the user, exposing the need to possibly share security encryption schemes to enable transactions. This may also be undesirable for banking institutions, as it may facilitate erosion of the transaction market to competitive forces.

Wrist Device/Watch. Small devices for the wrist are likely to apply messaging protocols such as SMS and will need small form factor profiles for the display of web based information. The technology is likely to also rely on intelligent voice interfaces due to form factor restrictions for both output and input command operation.

Eye-ware and Augmented Reality Devices. Devices with viewing screens such as head-up displays and transparent augmented reality screens will provide additional information when viewing objects and entities. Some recent trials have included additional customer information displayed to branch tellers using eye-ware and branch locaters using mobile devices. It is difficult to predict if such devices will become mainstream however, the important consideration is that diversity in technology is likely to continue and hence any proposed multi-channel architecture requires a flexible framework to be able to support newer devices and channels as they appear.

\section{A Multi-Channel Banking Architecture}

Building upon the technologies and defined distribution channels of the previous sections, and the experiences from applying related channel concepts in the broader industry, we now present a multi-channel architecture for banking. We focus the architecture upon those distribution channels which have a technology interface directly used by the banking customer, hence we omit channels such as branches and representatives that leverage internal systems for performing functions on behalf of the customer. The proposed architecture is shown at Figure 1, illustrating a layered framework where customer devices are used to access financial services via a set of networks and gateways that route requests to channel specific applications and services. The channel specific applications leverage the shared core banking functions via advertised SOA services and business processes of the integration layer.

The layered approach for separation of service capability together with the use of common services at the integration layer facilitates the deployment of new channel applications and services as they emerge. We now describe each of the components within the defined layers and in the following section 4, illustrate how this system architecture functions with several interaction scenarios that demonstrate these components in operation to fulfill financial requests made by the customer.

\subsection{Customer Devices}

The devices and technology used by customers have evolved considerably since the first deployment of self service automatic teller machines. Mainstream banking relies heavily upon the Internet channel with more recent trends showing a migration of use to mobile devices. Hence, the key channel devices of this layer include Web and mobile devices. The traditional services from phone, ATM, and EFTPos are continually being extended with new transactions and capabilities. An important consideration with customer devices is that this is a highly volatile layer with, for example, new mobile devices released every 12 to 18 months. This has disruptive downstream effects on the components of subsequent layers required to support the operation of these devices. 


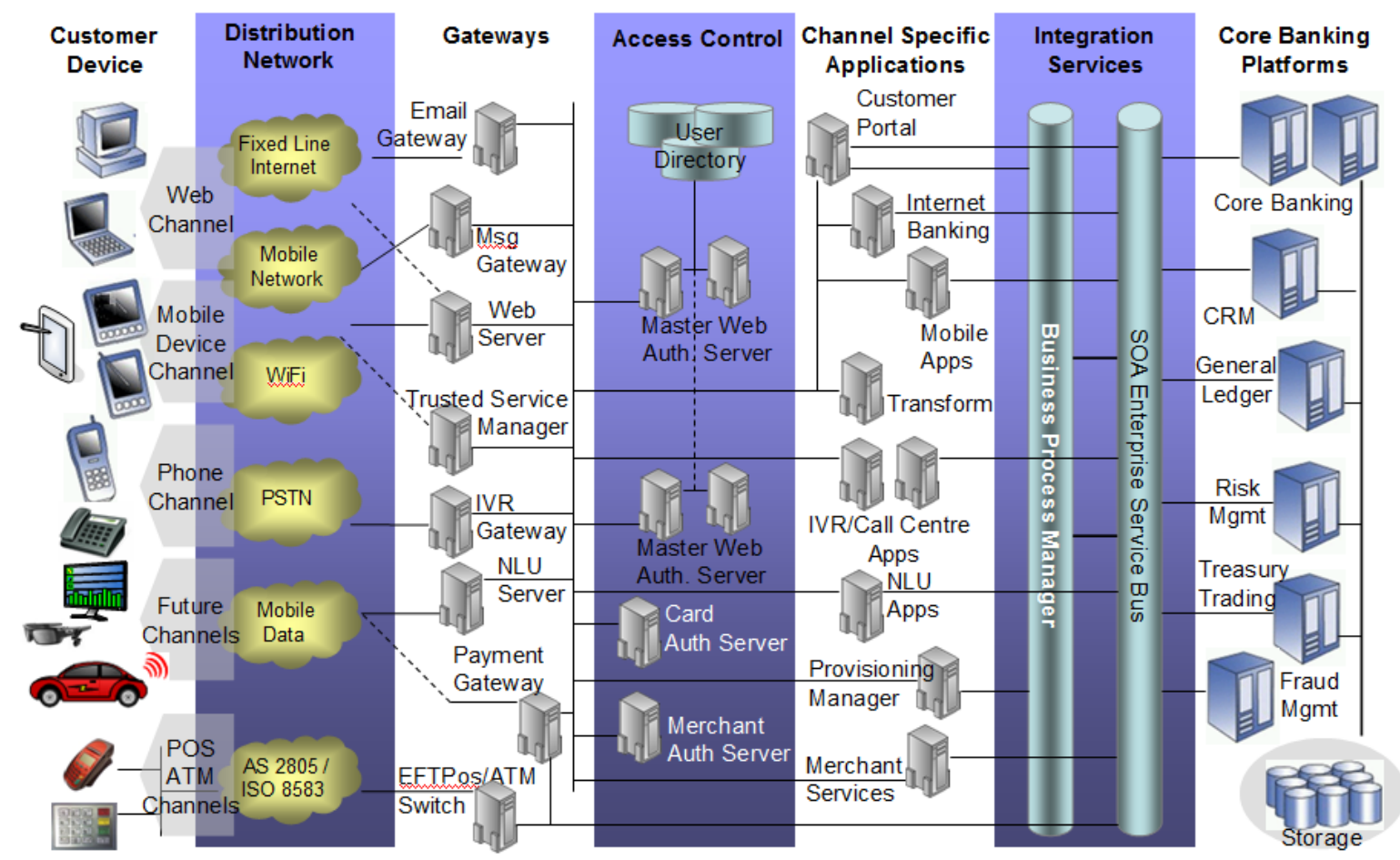

Figure 1. Blueprint for Multi-channel Banking Architecture

\subsection{Distribution Network}

The distribution networks are largely intended to be a seamless component within the set of infrastructure comprising the multi-channel system. The distribution networks include fixed line data networks supporting the Internet, mobile data networks for cellular phones, hotspots and WiFi networks, and more traditional networks such as the Public Switched Telephone Network (PSTN) and EFTPos/ATM networks based on ISO8583 (AS2805 in Australia). The supported networks and largely determined by the popular devices available on the market and require channel supported gateways to enable distribution of financial services. Future networks will appear, however these are likely to be extensions to existing network technologies with increases in data bandwidth to support more complex user interactions. Network awareness is an important design consideration for the multi-channel architecture, as the critical requirement exists for securing sensitive financial content over an increasingly more public network.

\subsection{Gateways}

The components making up the Gateway layer include web related gateways such as email, messaging (SMS, MMS), and HTTP Web Servers; these nodes will service web traffic from either fixed or mobile network channels. Integrated voice response gateways are deployed as web oriented servers transforming inbound and outbound speech into corresponding text for application servers at the channel specific layer. Future channels such as embedded devices within the car will be more dependent upon speech interfaces and state of the art technologies such as natural language understanding and processing are likely to provide the necessary language conversion to give customers more seamless interaction. Components at this layer are also responsible for establishing an encrypted channel for securing all communications between the customer and the bank. Incumbent technologies also reside at this layer such as EFPOS/ATM switches, for routing transactions and card verification, and payment gateways for HTTP originating car payments. 


\subsection{Access Control}

The key components making up the access control layer include the Master Authentication Server for the Internet related channels, and Merchant Authentication server for merchant account authentication services. The Master Web authentication server provides the identity and access management capabilities, as a single sign-on function, for customers accessing financial services from the web, mobile, and phone channels. As newer channels emerge additional clusters may be deployed to cater for the increasing authentication workload. Merchant Authentication Servers provide access to merchant services such as funds capture, reporting, account and transaction fee management.

\subsection{Channel Specific Applications}

Following on from the observation of the need to support a rapidly changing device market, there are flow-on affects to both the gateways and channel specific applications. Moreover, the supporting gateways and applications require similar agility in supporting new device capabilities, requiring revision and upgrade in accordance with the new features provided by these devices; where use is made of the device features by the distribution channel. In some instances this may be form factor adjustments, for viewing financial services, through to new mobile applications supporting newer web technologies (i.e. Flash, Java, Javascript). As newer tools appears (i.e. NLU), applications to support the requirements may be deployed at this layer addressing future distribution channels as required.

\subsection{Integration Services}

A key principle supported by the proposed layered architecture is that this provides a form of abstraction of the device specific requirements from the remaining layers of the system. Hence, changes in device capability are accommodated largely before and at the channel specific layer, with any additional functions supplied by the gateways. This means the processes and core banking systems are able to function in a relatively stable environment without being impacted by these changes. This is further facilitated by the use of an enterprise service bus and business process manager advertising capabilities to upstream and downstream systems.

\subsection{Core Banking Platforms}

The core banking platforms provide a stable and secure environment for executing the large volume of financial transactions and operational support functions managed by the bank. Although the number and type of core banking systems varies between institutions the key systems illustrated are used to support the most common financial activities, (refer Figure 1). This includes the central core banking platforms for accounts, loans, assets; customer relationship management (CRM) system; general ledger for managing accounts payable, receivable, etc; risk management for assessing customer accounts and transactions; treasury and trading systems; and fraud management systems on all financial activities. At the right most end of the multi-channel spectrum, the layered approached is intended to facilitate stability from change, as these core banking platforms provide foundation capabilities for a greater time span in comparison to the applications and devices in closer proximity to the customer which are more subject to change.

\section{ANALYSIS OF ARCHITECTURE: SYSTEM INTERACTIONS}

We now analyze the proposed multi-channel architecture by illustrating how the various components of the blueprint interact when a request is initiated by the customer via one of the 
defined channels. The interaction diagrams are UML based system interactions that are useful in mapping component function to specific platforms, this may assist in commercial product selection when building a multi-channel platform.

\subsection{Customer transfer funds to another bank using Web Channel}

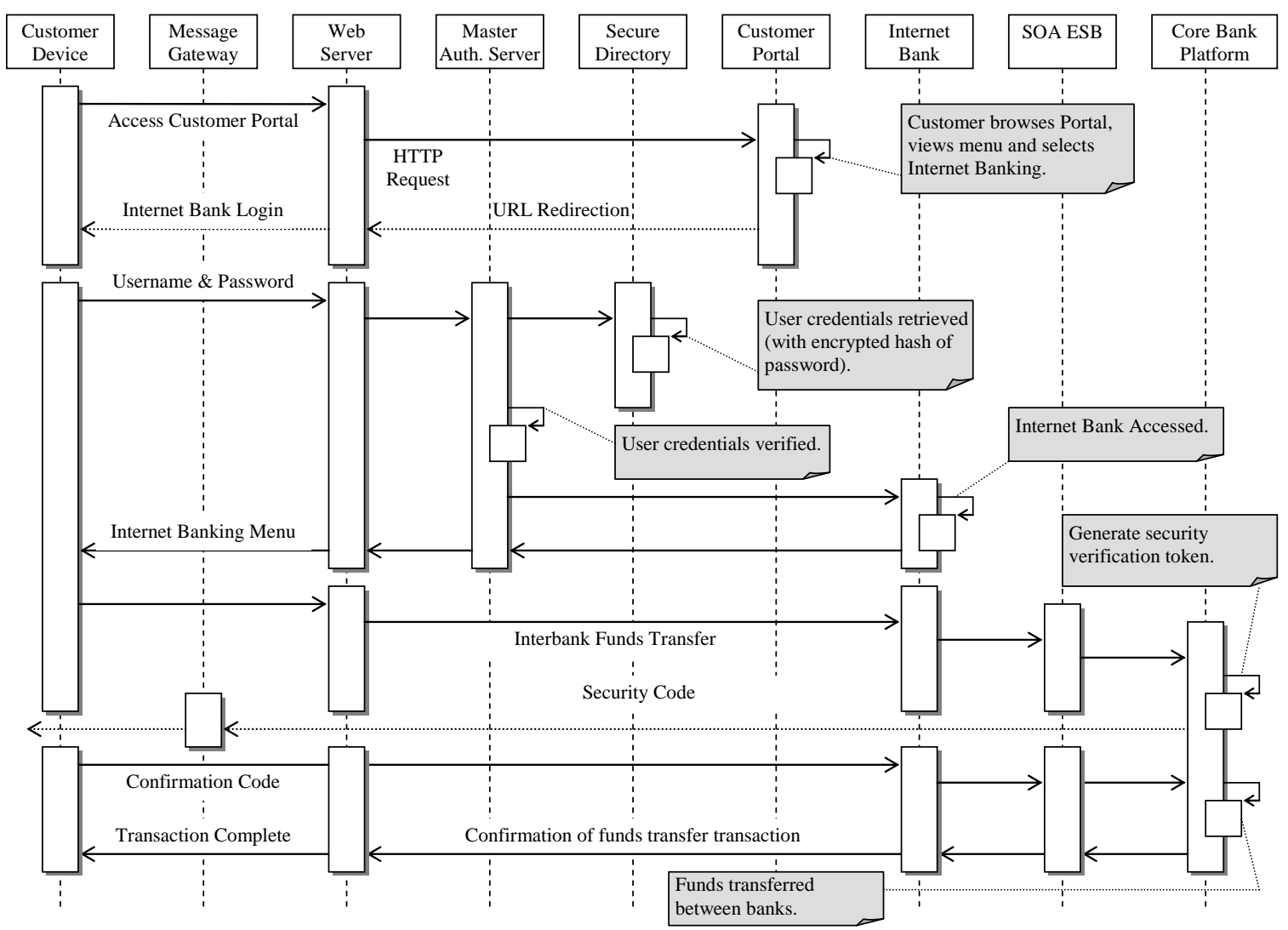

Figure 2. Web Channel Interaction

The interaction diagram shown at Figure 2 illustrates how the components of the proposed framework interact when processing a request by the customer to transfer funds to another account holder at a different financial institution. The customer initially accesses the customer banking portal and makes a request to view their banking accounts. After entering their username and password, the credentials are forwarded onto the Web Master Authentication server and verified against the secured user directory. Once authenticated, the bank account details are then returned to the customer. A funds transfer may then be initiated by the user, with an intermediate authentication challenge to the user returned to verify the requested funds transfer; with a security code sent (for example) to the customers' mobile phone. The customer responds to the transaction challenge and the funds transfer is carried out by the core banking platform.

\subsection{Customer applies for credit card limit increase using Mobile Device Channel}

Omitting the first two steps shown in the previous example (which are the same) we now describe the system interactions when a customer applies for a credit card limit increase using a mobile device, see Figure 3. In this example the customer accesses the Internet banking site using the mobile device, submitting an on-line form or request for an increase upon one of their selected payment cards. The request is then passed onto the business process manager, which initiates an 
automated business workflow for approving and setting the revised credit card limit at the core banking platform. Once the limit increase is approved, the customer may be optionally notified using a range of methods. Given the rise in malicious email over the internet, such notifications are either sent to the mobile phone, a physical post letter mail, or may appear as a message directly on the Internet banking account for viewing by the customer when they next access their accounts.

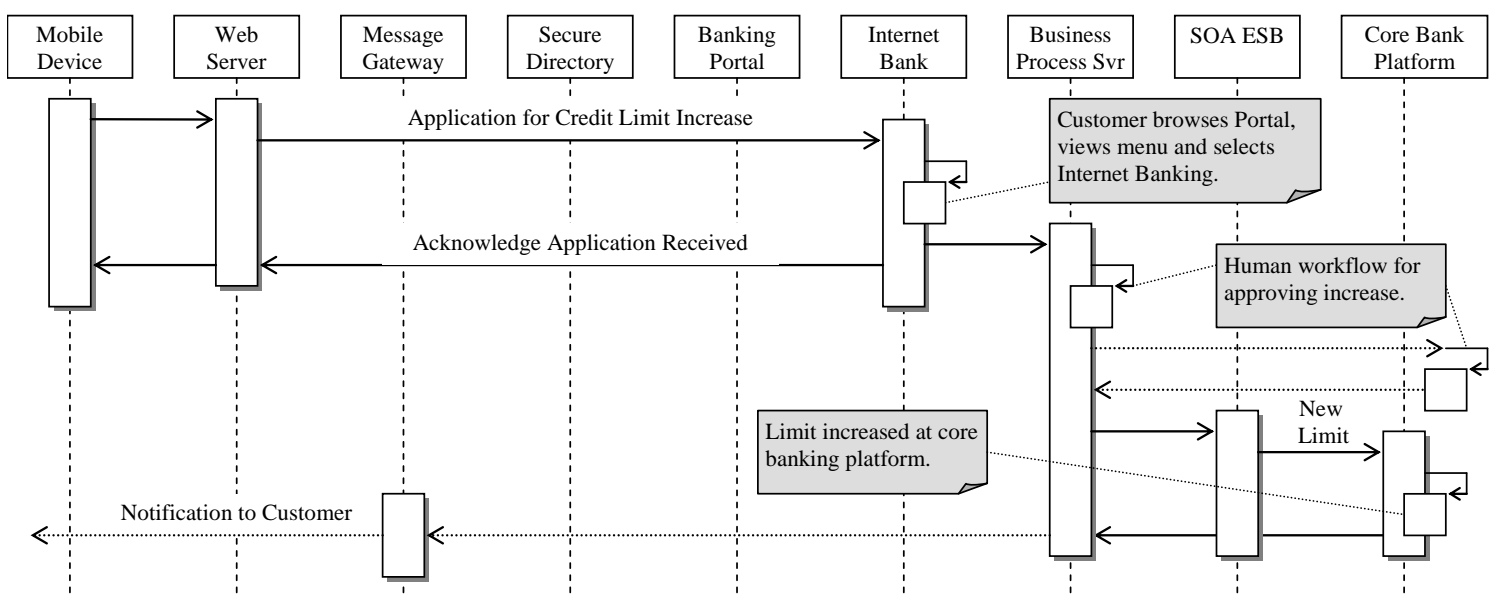

Figure 3. Mobile Channel Interaction

\subsection{Customer makes purchase using eWallet using Point of Sale Channel}

The final interaction example summarizes how the components collaborate when processing a request to make payment using a mobile device, with an embedded eWallet, over a point of sale merchant terminal. Initially the bank will provision the customer's payment card details to the smart card (SIM) on their mobile phone, this involves a request via the Trusted Service Manager (TSM) to the bank and once authenticated the corresponding account details are securely provisioned to the mobile phone using the banks Provisioning Manager. There are several entities that may mange and deploy the Trusted Service manager [14], however we assume that bank has deployed this component to maximize several benefits discussed in [15]. When the eWallet card is provisioned this is also activated at the corresponding core banking platform, refer to Figure 4. 


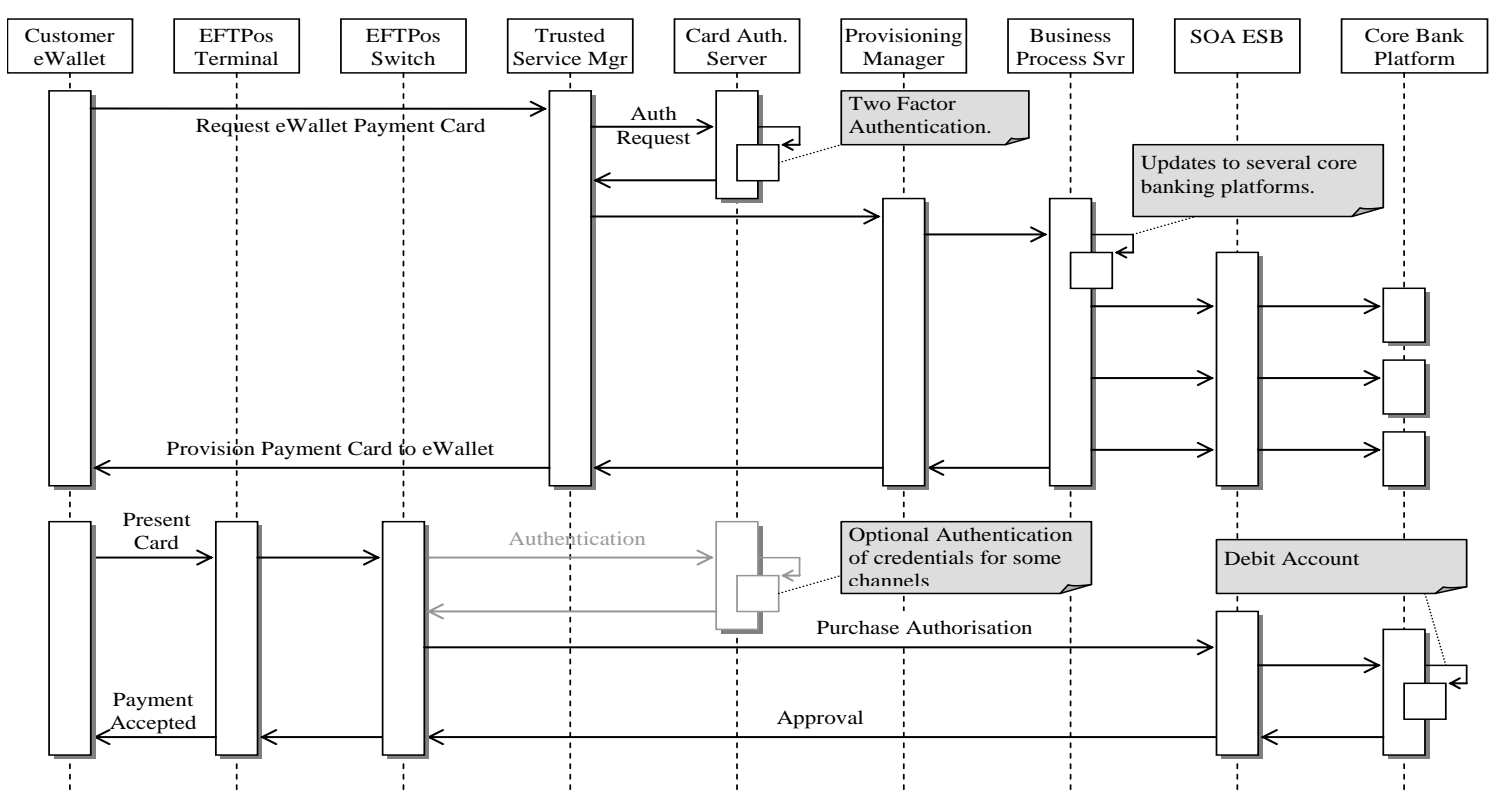

Figure 4. eWallet and Eftpos Channel Interaction

When the customer is ready to purchase an item they move their mobile phone in close proximity to the EFTPos terminal supporting a contactless near field communications system. The payment authorization request is sent over the EFTPos financial network and forwarded for approval (optionally, the credentials are verified by the payment card authentication service for some web channels). An SOA ESB service (this may normally form part of core banking platform for increased performance) is invoked to verify and then process the purchase authorization request; this is to determine if sufficient funds are available with the account subsequently debited at the core banking platform. The approval is then returned to the customer device. Funds capture is processed at later stage using conventional merchant capture batch transactions. The deployment of key technologies such as the TSM within the bank, help to enable this type of distribution channel using emerging technologies in a way that is seamless to the customer.

\section{CONCLUSIONS AND DISCUSSION}

As banking institutions continue to innovate with emerging technologies [16, 17], there is increased motivation to establish a technology framework for adopting new distribution channels and technologies. Customers are proving to be more tech-savvy and hence will trend towards the use of emerging devices to carry out their financial and business activities. In this paper we have outlined a multi-channel system architecture for banking, illustrating how the system component interact in practice. The proposed framework follows are layered architecture approach that facilitates deployment of new technologies, with a view to minimizing disruption to core banking platforms. The traditional banking channels for conducting commerce are facing increased competition from new entrants using internet technologies for conducting financial transactions. Banks that are able to apply these emerging technologies and support new channels using new payment instruments will be better placed to serve customers following these trends in device adoption. It is hoped that the proposed architecture and approach is of use as a blueprint to other financial institutions developing their programs for future multi-channel banking systems.

There is further work to clarify the business processes associated with the framework proposed, including business activities for supporting and maintaining the emerging channels discussed. In 
addition there is more work required to define the security architectures required to support the systems for a multi-channel bank as newer threats emerge through the use of newer technologies. Moreover, it is anticipated that as new client side applications and devices are brought to the market, attackers will target these areas attempting to exploit security exposures in these technologies.

\section{ACKNOWLEDGEMENTS}

We thank Sonia Basser and Wesley Allen for their guidance and their instructive comments on the format and content of this paper.

\section{REFERENCES}

[1] C.J. Pavlovski, "Service Delivery Platforms in Practice", IEEE Communications Magazine, vol. 45, no. 3, March 2007, pp. 114-121.

[2] T. Kamogawa and H. Okada, "Enterprise Architecture and Information Systems - In Japanese Banking Industry", International Symposium on Applications and the Internet. IEEE, 2008, pp. 433-436.

[3] J. Sun and Y. Chen, "Building a Common Enterprise Technical Architecture for an Universal Bank", International Conference on Management and Service Science (MASS), 2010, pp. 1-4.

[4] R. Winter and R. Fischer, "Essential Layers, Artifacts, and Dependencies of Enterprise Architecture", Journal of Enterprise Architecture, Vol. 3, Issue 2, May 2007.

[5] K. Pousttchi and M. Schurig, "Assessment of Today's Mobile Banking Applications from the View of Customer Requirements", Proceedings of the 37th Hawaii International Conference on System Sciences - 2004, pp. 1-10.

[6] M.K. Harma and R. Dubey, "Prospects of technological advancements in banking sector using Mobile Banking and position of India", International Association of Computer Science and Information Technology, 2009, pp. 291-295

[7] P. Chandrahas, D. Kumar, et. al., "Some Design Considerations for a Mobile Payment Architecture", National Conference on Communications (NCC), 2011, pp. 1-5.

[8] S.K. Bhosale, "Architecture of a Single Sign on (SSO) for Internet Banking", IET International Conference on Wireless, Mobile and Multimedia Networks, 2008. IET pp. 103-105.

[9] C.Narendiran, S.A. Rabara, and N.Rajendran, "Performance Evaluation on End-to-End Security Architecture for Mobile Banking System", 1st IFIP Wireless Days, 2008, pp. 1-5.

[10] H. Reza and N. Mazumder, "A Secure Software Architecture for Mobile Computing", 9th International Conference on Information Technology- 2012, pp. 566-571.

[11] C. Möckel, "Usability and Security in EU E-Banking Systems: Towards an Integrated Evaluation Framework", International Symposium on Applications and the Internet, 2011, pp. 230-233.

[12] A. Carignani, M. De Marco, and C. Rosenthal-Sabroux, "Supporting a multiple channel architecture design: the UML contribution in a virtual banking environment", ECIS 2000 Proceedings. Paper 21. pp. 883-888.

[13] S. Mitchell, C.J. Pavlovski, et al. "Multimodal Natural Language Platform Supporting Cellular Phones", The ACM Journal of Mobile Computing and Communications Review (MC2R), ACM Sigmobile, Vol.10, Iss.3, pp. $34-45,2006$.

[14] C. Cox, "Trusted Service Manager: The Key to Accelerating Mobile Commerce", FirstData, 2009. http://www.firstdata.com/downloads/thought-leadership/fd_mobiletsm_whitepaper.pdf

[15] D. Worthington, "Five Reasons Why Banks Should be their own TSMs", BellId, 2012. http://www.bellid.com/media1/blog/view/17-5-reasons-why-banks-should-be-their-own-tsms

[16] Business Wire, "U.S. Bank Introduces Augmented Reality iPhone ${ }^{\circledR}$ Application to Find Branches and ATMs", 2012. http://www.businesswire.com/news/home/20120411005193/en/U.S.-Bank-Introduces-Augmented-RealityiPhone

[17] PrivatBank, "PrivatBank ready for customer service with Google Glass", Press Release, April 2013. http://www.privatbank.lv/en/presscenter/pressrelease/2013/news2013-04-001/.

\section{Author}

Chris Pavlovski is an IBM Distinguished Engineer and Chief Technology Advisor in Finance and Banking for IBM Australia. He is a member of the IBM Academy of Technology, an Open Group Master Certified Architect, and a Fellow of the Institution of Engineering and Technology (IET). He has a $\mathrm{PhD}$ in cryptography and electronic commerce.

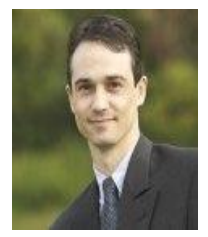

